\title{
Obesity-related adjunctive systo-diastolic ventricular dysfunction in patients with hypertension: echocardiographic assessment with tissue Doppler velocity and strain imaging
}

\author{
Massimo Leggio ${ }^{1}$, Giancarlo Cruciani ${ }^{2}$, Luca Sgorbini ${ }^{3}$, Andrea Mazza ${ }^{4}$, Maria Grazia Bendini ${ }^{4}$, \\ Marco Pugliese ${ }^{5}$, Francesco Leggio ${ }^{3}$ and Anna Patrizia Jesi ${ }^{1}$
}

Very few data exist regarding the effect of obesity on both left and right systo-diastolic ventricular function in hypertensive patients. Therefore, the aim of this study was to determine the existence and extent of an obesity-related adjunctive depressive effect on left- and right-ventricular systo-diastolic dysfunction. This study compared non-obese with obese hypertensive patients and evaluated left- and right-ventricular morphological and functional parameters by means of conventional echocardiography and by two new sensitive echocardiographic techniques: tissue Doppler velocity and strain imaging. We selected 248 hypertensive patients and divided them into four groups according to increasing body mass index (BMI). All patients underwent a clinical history and examination and transthoracic echocardiography, including conventional echocardiographic evaluation and tissue Doppler velocity and strain imaging measurements. Conventional echocardiographic evaluation did not reveal an association between ventricular systo-diastolic dysfunction and increasing BMI. In contrast, tissue Doppler velocity and strain imaging measurements emphasized the negative influence of obesity. For measurements in both the left and right ventricle, myocardial early peak diastolic velocities $\left(E_{\mathrm{m}}\right)$, the ratio of myocardial early-to-late peak diastolic velocity $\left(E_{\mathrm{m}} / A_{\mathrm{m}}\right)$, myocardial peak systolic velocities $\left(S_{\mathrm{m}}\right)$, and peak strain and strain rate values significantly decreased with increasing BMI $(P<0.01$ for all parameters measured), even after adjusting for potential confounding variables. In conclusion, by means of new more sensitive echocardiographic techniques, our study clearly demonstrated the negative impact of obesity on both left- and right-ventricular systo-diastolic function, in terms of adjunctive sub-clinical worsening, in hypertensive patients.

Hypertension Research (2011) 34, 468-473; doi:10.1038/hr.2010.266; published online 13 January 2011

Keywords: diastolic ventricular function; echocardiography; obesity; systolic ventricular function.

\section{INTRODUCTION}

The prevalence of obesity, defined as a body mass index (BMI) $\geqslant 30 \mathrm{~kg} \mathrm{~m}^{-2}$, is dramatically increasing worldwide. ${ }^{1,2}$ Obesity is associated with a higher rate of cardiovascular morbidity and mortality. It is an independent risk factor for the development of heart failure, ${ }^{3}$ even after accounting for other comorbid conditions that cluster with it, such as diabetes and hypertension. ${ }^{4}$ Moreover, obesity has been associated with heart failure, ${ }^{5}$ left-ventricular dilation, increased leftventricular wall stress and compensatory (eccentric) left-ventricular hypertrophy. ${ }^{6,7}$

Impairment of cardiac function has been reported to correlate with BMI and the duration of obesity, ${ }^{7,8}$ with most studies demonstrating abnormal diastolic function, ${ }^{9,10}$ without a consistent association with systolic dysfunction. ${ }^{7,8}$ A condition characterized by chronic leftventricular volume overload, eccentric hypertrophy and progressive diastolic impairment, commonly leading to heart failure, have also been described as a unique entity named 'obesity cardiomyopathy'. ${ }^{6}$ Indeed, obesity has been linked to a spectrum of more minor cardiovascular changes, ranging from hyperdynamic circulation to sub-clinical cardiac structural changes. ${ }^{5,6}$ These early manifestations may be important because treatment to reverse this process is most likely to be effective earlier in the disease. More recently, it has been suggested that even milder degrees of obesity may negatively affect cardiac performance by means of subtle alterations in left-ventricular structure and morphology, and alterations in either sub-clinical or clinical systo-diastolic mechanics. ${ }^{4,11,12}$ In addition, an association between sub-clinical right-ventricular dysfunction and obesity has also been reported. ${ }^{13}$

Furthermore, because these data were mainly derived from studies performed in otherwise healthy subjects with isolated obesity, the

${ }^{1}$ Cardiovascular Department, Cardiac Rehabilitation Operative Unit (SI), San Filippo Neri Hospital, Rome, Italy; ${ }^{2}$ Medicine Department, Geriatric Operative Unit (SI), San Filippo Neri Hospital, Rome, Italy; ${ }^{3}$ Cardiologic-Geriatric Department, Cardiologic Operative Unit, INRCA-IRCCS Hospital, Rome, Italy; ${ }^{4}$ Cardiology Division, Santa Maria della Stella Hospital, Orvieto, Italy and ${ }^{5}$ Cardiovascular Department, 1 Cardiologic Operative Unit, San Camillo-Forlanini Hospital, Rome, Italy 
limitations of this evidence must be recognized. Very few data exist regarding the effect of obesity on left- and right systo-diastolic ventricular function in hypertensive patients.

Therefore, the aim of this study was to evaluate left- and rightventricular morphological and functional parameters by means of conventional echocardiography and new sensitive echocardiographic techniques - tissue Doppler velocity and strain imaging — in non-obese and obese hypertensive patients.

\section{METHODS}

\section{Study characteristics and population}

By clinical-instrumental evaluation, we selected 248 patients, referred to our structures with a diagnosis of hypertension (at least three ambulatory resting measurements of systolic blood pressure $\geqslant 140 \mathrm{~mm} \mathrm{Hg}$ and/or diastolic blood pressure $\geqslant 90 \mathrm{~mm} \mathrm{Hg}$ ), who satisfied the following inclusion criteria:

1. No evidence of diabetes mellitus or other significant systemic diseases other than hypertension and non-syndromical obesity;

2. No evidence of significant organic cardiovascular disease, except hypertensive cardiomyopathy;

3. Presence of normal sinus rhythm with no abnormalities on electrocardiography;

4. Presence of adequate acoustic windows and normal echocardiographicDoppler parameters other than mitral transvalvular diastolic flow patterns and mild left-ventricular hypertrophy (end-diastolic interventricular septum and posterior wall thickness $\leqslant 14$ and $\leqslant 13 \mathrm{~mm}$, respectively), without any other underlying etiology;

5. Absence of drug therapy, other than ongoing antihypertensive drug therapy, that was stable for at least 2 months.

\section{Instrumental evaluation}

To exclude organic cardiovascular and systemic disease, patients underwent a clinical history and examination, a biochemical analysis, resting and stress electrocardiography and transthoracic echocardiography.

Four groups of hypertensive patients were identified according to their BMI: non-obese (BMI $<25 \mathrm{~kg} \mathrm{~m}^{-2} ; n=58$ ), overweight (BMI 25 to $30 \mathrm{~kg} \mathrm{~m}^{-2}$; $n=67$ ), mildly obese (BMI $30-35 \mathrm{~kg} \mathrm{~m}^{-2} ; n=63$ ) and severely obese (BMI $>35 \mathrm{~kg} \mathrm{~m}^{-2} ; n=60$ ).

All enrolled patients underwent Doppler echocardiography, with a commercially available standard ultrasound diagnostic system (Vivid 7, GE Vingmed, Horten, Norway), equipped with a $2.5-\mathrm{MHz}$ phased-array transducer. Images were obtained in the standard tomographic views of the left ventricle (parasternal long- and short-axis and apical four chamber, two chamber and long-axis views). All echocardiographic studies were digitally stored for off-line analysis. All measurements were averaged from three cardiac cycles to minimize respiratory variability, and were blind-performed twice by three different and independent expert sonographers (ML, LS and MGB) to minimize intra- and interobserver variabilities, expressed as a coefficient of variation. Left- and right ventricular end-diastolic and end-systolic diameters and septal, posterior, relative, right ventricular free wall thickness were obtained from the bi-dimensional-targeted monodimensional echocardiographic tracings in the parasternal long and short-axis scans according to the criteria of the American Society of Echocardiography guidelines, ${ }^{14,15}$ and then left-ventricular indexed end-diastolic and systolic volumes, left-ventricular ejection fraction (Simpson's biplane-modified method) and left-ventricular fractional shortening (left-ventricular end diastolic diameter-left-ventricular end-systolic diameter/left-ventricular end-diastolic diameter $\times 100)$ were calculated; left-ventricular mass index was determined by Devereux's formula and indexed to height to the power of 2.7.16 Right ventricular end-diastolic volumes and ejection fraction were calculated from apical four-chamber views using the area-length monoplane method $\left(V_{\mathrm{RV}}=3 / 8 \pi\left(\operatorname{area}^{2} /\right.\right.$ length $\left.)\right)$.

The Doppler's transvalvular parameters measured were mitral E and A wave peak velocities, the ratio of mitral early-to-late peak velocity, and early filling deceleration and isovolumic relaxation times, obtained in apical four-chamber echocardiographic windows by placing the sample volume at the level of the valve leaflet tips.

The processing of ultrasound and tissue Doppler signals provide a number of sensitive parameters of systolic and diastolic function that are less sensitive to loading and correlate with structural changes such as myocardial fibrosis. ${ }^{17}$ Tissue Doppler measurements have also been used to derive myocardial strain and strain rate, which are well-validated descriptors of shortening and lengthening that reflect tissue compressibility. ${ }^{11}$

Myocardial velocities were recorded by using color tissue Doppler imaging in each apical view, using a high frame rate $(120 \mathrm{MHz})$ and a temporal resolution of $8 \mathrm{~ms}$. Images were recorded and digitized, and derivation and analysis of tissue Doppler velocity profiles were performed off-line, using commercially available computer software (Echopac, GE Vingmed).

Strain and strain rate curves were extracted from color tissue Doppler images using standard software (Echopac, GE Vingmed). Peak strain was defined as the greatest value on the strain curve, and peak strain rate was measured from the strain curve as previously validated. ${ }^{18,19}$

Briefly, for all patients, mean values of myocardial peak systolic $\left(S_{\mathrm{m}}\right)$, early peak diastolic $\left(E_{\mathrm{m}}\right)$ and late peak diastolic velocities $\left(A_{\mathrm{m}}\right)$ of the septal, lateral, inferior and anterior regions of the mitral annulus were calculated. Values of $S_{\mathrm{m}}, E_{\mathrm{m}}$ and $A_{\mathrm{m}}$ of the lateral region of the tricuspid annulus, and of peak strain and strain rate values of the basal interventricular septum and the basal right ventricular free wall were also obtained. Ratios of mitral and tricuspid annulus myocardial early-to-late peak diastolic velocity $\left(E_{\mathrm{m}} / A_{\mathrm{m}}\right)$ were derived, and left-ventricular filling pressures were approximated from the relationship of early-diastolic mitral inflow/mitral annular velocity ratio.

\section{Statistical analysis}

Statistical analyses were performed with SPSS/PC for Windows release 11.0 dedicated software (SPSS Inc, Chicago, IL, USA). An estimation of inter-group differences between clinical, echocardiographic and generally quantitative characteristics was performed with an analysis of variance (ANOVA) by Dunnett's post-hoc test for multiple comparisons; categorical variables were analyzed by the $\chi^{2}$ test. Multivariate stepwise linear regression analysis was performed to assess the correlation between echocardiographic variables and BMI adjusted for age, gender, mean blood pressure, left-ventricular mass index, relative wall thickness and right-ventricular free wall thickness. All continuous variables and results are expressed as mean \pm s.d. with categorical variables as frequencies; $P$-values $<0.05$ were considered statistically significant.

\section{RESULTS}

\section{Clinical characteristics}

Descriptive clinical and echocardiographic characteristics of the four groups of patients are summarized in Table 1. All patients were on antihypertensive therapy. Given that differences in weight, body surface area and BMI reflect the patients' categorization, no other significant variations (age, gender, heart rate, smoking status, systolicdiastolic-mean blood pressure or type of antihypertensive drug therapy) were identified. The results of biochemical analyses (renal function, electrolytes, fasting plasma glucose and lipid profile), and of resting and stress electrocardiography were normal in all patients, with no significant differences between the groups.

\section{Echocardiographic characteristics}

With increasing BMI, conventional echocardiography (Table 2) revealed a significant increase only for septal and posterior wall thickness, left-ventricular mass index $(P<0.001$ for all $)$, relative and right-ventricular free wall thickness $(P<0.05$ for all). With regard to Doppler transvalvular parameters, only isovolumic relaxation and early filling deceleration times $(P<0.05$ for all) showed a significant modification. This was likely because of the influence of hemodynamic conditions on mitral early-late peak velocity measurements that 
Table 1 Main characteristics of the study population

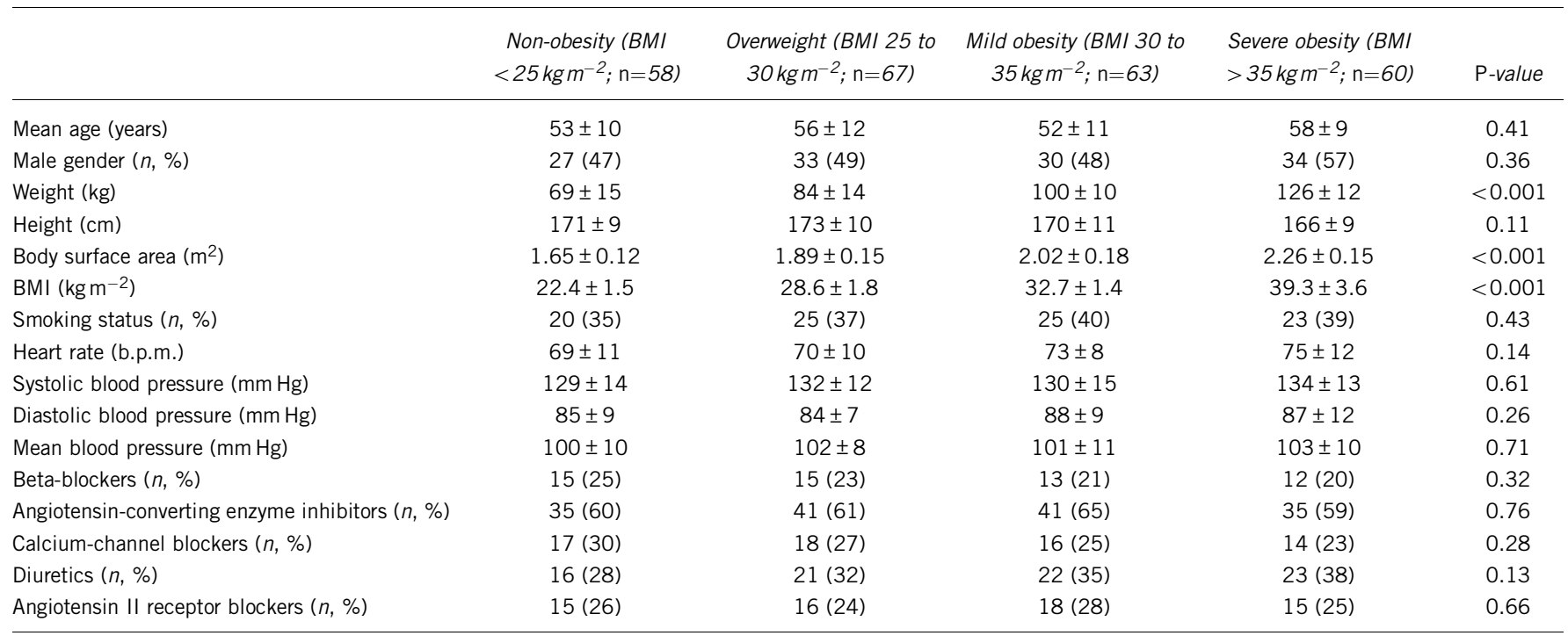

Abbreviations: BMI, body mass index; b.p.m., beat per minute.

Table 2 Conventional echocardiographic parameters

\begin{tabular}{|c|c|c|c|c|c|}
\hline & $\begin{array}{l}\text { Non-obesity (BMI } \\
<25 \mathrm{kgm}^{-2} ; \mathrm{n}=58 \text { ) }\end{array}$ & $\begin{array}{l}\text { Overweight (BMI } 25 \text { to } \\
\quad 30 \mathrm{~kg} \mathrm{~m}^{-2} ; \mathrm{n}=67 \text { ) }\end{array}$ & $\begin{array}{l}\text { Mild obesity (BMI } 30 \text { to } \\
\qquad 35 \mathrm{~kg} \mathrm{~m}^{-2} ; \mathrm{n}=63 \text { ) }\end{array}$ & $\begin{array}{l}\text { Severe obesity (BMI } \\
\left.>35 \mathrm{~kg} \mathrm{~m}^{-2} ; \mathrm{n}=60\right)\end{array}$ & P-value \\
\hline LVEdD (mm) & $47.2 \pm 3.9$ & $48.6 \pm 4.5$ & $48.1 \pm 4.9$ & $49.8 \pm 5.1$ & 0.16 \\
\hline LVEsD (mm) & $26.9 \pm 4.2$ & $28.5 \pm 4.4$ & $29.0 \pm 4.7$ & $28.9 \pm 5.0$ & 0.22 \\
\hline FS (\%) & $34.6 \pm 3.9$ & $35.7 \pm 4.8$ & $35.2 \pm 4.6$ & $34.8 \pm 5.2$ & 0.68 \\
\hline LVEdV (ml) & $107.2 \pm 25.3$ & $108.9 \pm 27.1$ & $109.5 \pm 30.6$ & $111.8 \pm 31.7$ & 0.12 \\
\hline LVEsV (ml) & $36.5 \pm 11.8$ & $37.9 \pm 12.2$ & $38.5 \pm 13.0$ & $39.3 \pm 13.5$ & 0.20 \\
\hline LVEF (\%) & $66.7 \pm 6.4$ & $67.2 \pm 6.0$ & $66.9 \pm 7.3$ & $66.5 \pm 7.6$ & 0.54 \\
\hline SWT (mm) & $11.2 \pm 1.04$ & $12.0 \pm 1.06$ & $12.5 \pm 0.98$ & $12.8 \pm 1.12$ & $<0.001$ \\
\hline PWT (mm) & $10.3 \pm 0.89$ & $11.0 \pm 1.14$ & $11.4 \pm 1.20$ & $11.7 \pm 1.15$ & $<0.001$ \\
\hline LVMi $\left(\mathrm{g} \mathrm{m}^{-2.7}\right)$ & $42.5 \pm 14.9$ & $48.7 \pm 19.2$ & $54.9 \pm 18.6$ & $59.8 \pm 22.3$ & $<0.001$ \\
\hline RWT (mm) & $0.46 \pm 0.09$ & $0.48 \pm 0.07$ & $0.51 \pm 0.06$ & $0.50 \pm 0.08$ & $<0.05$ \\
\hline RVEdD (mm) & $21.6 \pm 1.3$ & $22.5 \pm 1.2$ & $23.0 \pm 1.4$ & $23.8 \pm 1.9$ & 0.31 \\
\hline RVFWT (mm) & $3.3 \pm 0.74$ & $3.8 \pm 0.94$ & $3.9 \pm 0.78$ & $4.1 \pm 1.2$ & $<0.05$ \\
\hline RVEdV (ml) & $38.2 \pm 14.7$ & $40.9 \pm 17.7$ & $42.4 \pm 18.9$ & $43.9 \pm 16.5$ & 0.09 \\
\hline RVEF (\%) & $53.2 \pm 7.3$ & $54.9 \pm 5.7$ & $52.8 \pm 6.9$ & $51.0 \pm 8.3$ & 0.36 \\
\hline$E\left(\mathrm{~cm} \mathrm{~s}^{-1}\right)$ & $76.5 \pm 17.0$ & $74.2 \pm 16.5$ & $74.4 \pm 18.2$ & $73.7 \pm 17.9$ & 0.64 \\
\hline$A\left(\mathrm{~cm} \mathrm{~s}^{-1}\right)$ & $80.2 \pm 15.8$ & $81.3 \pm 16.8$ & $82.0 \pm 17.4$ & $84.5 \pm 16.6$ & 0.49 \\
\hline$E / A$ & $0.92 \pm 0.3$ & $0.90 \pm 0.5$ & $0.89 \pm 0.6$ & $0.88 \pm 0.9$ & 0.55 \\
\hline IVRT (ms) & $94.0 \pm 18.7$ & $102.5 \pm 17.4$ & $108.7 \pm 18.3$ & $117.2 \pm 16.1$ & $<0.05$ \\
\hline DT (ms) & $232.4 \pm 26.7$ & $242.6 \pm 33.2$ & $254.8 \pm 38.7$ & $271.3 \pm 45.1$ & $<0.05$ \\
\hline
\end{tabular}

Abbreviations: A, mitral late peak velocity; BMI, body mass index; DT, early filling deceleration time; E, mitral early peak velocity; E/A, ratio of mitral early-to-late peak velocity; FS, fractional shortening; IVRT, isovolumic relaxation time; LVEdD, left-ventricular end-diastolic diameter; LVEdV, left-ventricular end-diastolic volume; LVEF, left-ventricular ejection fraction; LVEsD, leftventricular end-systolic diameter; LVEsV, left-ventricular end-systolic volume; LVMi, left-ventricular mass index; PWT, posterior wall thickness; RVEdD, right-ventricular end-diastolic diameter; RVEdV, right-ventricular end-diastolic volume; RVEF, right-ventricular ejection fraction; RVFWT, right-ventricular free wall thickness; RWT, relative wall thickness; SWT, septal wall thickness.

revealed a mild degree of diastolic dysfunction in the referent group of non-obese hypertensive patients that did not significantly worsen with increasing BMI. These results corroborated that left-ventricular systodiastolic dysfunction was not associated with obesity in hypertensive patients.

In contrast, tissue Doppler velocity and strain imaging measurements (Table 3) demonstrated and highlighted the negative influence of obesity. For both the left and right ventricles $E_{\mathrm{m}}(P<0.01)$ and the $E_{\mathrm{m}} / A_{\mathrm{m}}$ ratio $(P<0.001)$ significantly decreased with increasing $\mathrm{BMI}$, suggesting an obesity-related diastolic dysfunction; this was confirmed by the increase of the left-ventricular filling pressures, approximated by the early-diastolic mitral inflow/mitral annular velocity ratio $(P<0.001)$. Furthermore, for both the left and right ventricles, obesity-related systolic dysfunction was also detected; in fact, $S_{\mathrm{m}}$ $(P<0.01$ and $<0.001$, respectively $)$ and peak strain $(P<0.001)$ and strain rate values $(P<0.01$ and $<0.001$, respectively $)$ were slightly reduced with increasing $B M I$.

To avoid the effect of some potentially confounding variables, these were entered into a multivariate linear stepwise regression model. However, even after adjusting for age, gender, mean blood pressure, 
Table 3 Tissue Doppler and strain imaging echocardiographic parameters

\begin{tabular}{|c|c|c|c|c|c|}
\hline & $\begin{array}{l}\text { Non-obesity (BMI } \\
<25 \mathrm{~kg} \mathrm{~m}^{-2} ; \mathrm{n}=58 \text { ) }\end{array}$ & $\begin{array}{l}\text { Overweight (BMI } 25 \text { to } \\
30 \mathrm{~kg} \mathrm{~m}^{-2} ; \mathrm{n}=67 \text { ) }\end{array}$ & $\begin{array}{l}\text { Mild obesity (BMI } 30 \text { to } \\
35 \mathrm{~kg} \mathrm{~m}^{-2} ; \mathrm{n}=63 \text { ) }\end{array}$ & $\begin{array}{l}\text { Severe obesity (BMI } \\
>35 \mathrm{~kg} \mathrm{~m}^{-2} ; \mathrm{n}=60 \text { ) }\end{array}$ & $\mathrm{P}$-value \\
\hline $\operatorname{LVS}_{\mathrm{m}}\left(\mathrm{cm} \mathrm{s}^{-1}\right)$ & $7.34 \pm 1.7$ & $6.51 \pm 1.5$ & $5.72 \pm 1.8$ & $4.96 \pm 2.0$ & $<0.01$ \\
\hline $\operatorname{LVA}_{\mathrm{m}}\left(\mathrm{cm} \mathrm{s}^{-1}\right)$ & $7.19 \pm 2.0$ & $7.78 \pm 1.8$ & $8.06 \pm 1.7$ & $8.24 \pm 1.9$ & 0.09 \\
\hline $\mathrm{LVE}_{\mathrm{m}} / \mathrm{LVA}_{\mathrm{m}}$ & $0.96 \pm 1.9$ & $0.83 \pm 1.6$ & $0.67 \pm 1.8$ & $0.56 \pm 1.9$ & $<0.001$ \\
\hline$E / L V E_{m}$ & $10.6 \pm 2.0$ & $12.3 \pm 2.7$ & $14.4 \pm 2.9$ & $16.9 \pm 3.2$ & $<0.001$ \\
\hline $\mathrm{RVA}_{\mathrm{m}}\left(\mathrm{cm} \mathrm{s}^{-1}\right)$ & $8.94 \pm 1.6$ & $9.16 \pm 1.5$ & $9.55 \pm 1.6$ & $9.98 \pm 1.8$ & 0.12 \\
\hline $\mathrm{RVE}_{\mathrm{m}} / \mathrm{RVA}_{\mathrm{m}}$ & $1.04 \pm 1.5$ & $0.90 \pm 1.3$ & $0.78 \pm 1.6$ & $0.61 \pm 1.4$ & $<0.001$ \\
\hline LVS (\%) & $24.44 \pm 3.5$ & $21.23 \pm 3.0$ & $19.14 \pm 3.6$ & $16.42 \pm 3.9$ & $<0.001$ \\
\hline LVSR $\left(\right.$ LVS $\left.^{-1}\right)$ & $1.88 \pm 0.3$ & $1.76 \pm 0.6$ & $1.53 \pm 0.4$ & $1.40 \pm 0.5$ & $<0.01$ \\
\hline RVS (\%) & $27.56 \pm 4.0$ & $24.55 \pm 3.8$ & $22.39 \pm 3.9$ & $20.14 \pm 4.1$ & $<0.001$ \\
\hline $\operatorname{RVSR}\left(\right.$ RVS $\left.^{-1}\right)$ & $1.91 \pm 0.5$ & $1.63 \pm 0.7$ & $1.49 \pm 0.8$ & $1.31 \pm 0.9$ & $<0.001$ \\
\hline
\end{tabular}

Abbreviations: BMI, body mass index; E/LVE $E_{m}$, ratio of mitral early peak velocity/mitral annulus early peak diastolic velocity; LVA $A_{m}$ mitral annulus late peak diastolic velocity; LVE $E_{m}$, mitral annulus early peak diastolic velocity; $\mathrm{LVE}_{\mathrm{m}} / \mathrm{LVA}_{\mathrm{m}}$, ratio of mitral annulus early-to-late peak diastolic velocity; LVS, basal interventricular septum peak strain value; LVS $\mathrm{m}_{\mathrm{m}}$, mitral annulus peak systolic velocity; LVSR, basal interventricular septum peak strain rate value; RVA $A_{m}$, tricuspid annulus late peak diastolic velocity; RVE $E_{m}$, tricuspid annulus early peak diastolic velocity; RVE /RVA $_{m}$, ratio of tricuspid annulus early-to-late peak diastolic velocity; RVS, basal right-ventricular free wall peak strain value; RVS $\mathrm{m}_{\mathrm{m}}$, tricuspid annulus peak systolic velocity; RVSR, basal right-ventricular free wall peak strain rate value.

Table 4 Multivariate independent predictors of left-ventricular echocardiographic variables in overweight and obese patients

\begin{tabular}{|c|c|c|c|c|c|c|c|c|}
\hline & \multicolumn{2}{|c|}{$L V S_{m}\left(R^{2}=0.19\right)$} & \multicolumn{2}{|c|}{$L V E_{m}\left(\mathrm{R}^{2}=0.28\right)$} & \multicolumn{2}{|c|}{$\operatorname{LVS}\left(\mathrm{R}^{2}=0.26\right)$} & \multicolumn{2}{|c|}{$\operatorname{LVSR}\left(\mathrm{R}^{2}=0.32\right)$} \\
\hline & $\beta$ & P-value & $\beta$ & P-value & $\beta$ & P-value & $\beta$ & P-value \\
\hline BMI $\left(\mathrm{kg} \mathrm{m}^{-2}\right)$ & -0.43 & $<0.01$ & -0.40 & $<0.01$ & -0.38 & $<0.01$ & -0.41 & $<0.01$ \\
\hline Age (in years) & -0.18 & 0.10 & -0.20 & 0.09 & -0.16 & 0.13 & -0.13 & 0.20 \\
\hline Male gender & 0.16 & 0.21 & 0.19 & 0.15 & 0.20 & 0.13 & 0.14 & 0.24 \\
\hline Mean blood pressure $(\mathrm{mm} \mathrm{Hg})$ & -0.10 & 0.31 & -0.13 & 0.26 & -0.12 & 0.28 & -0.15 & 0.22 \\
\hline LVMi $\left(\mathrm{g} \mathrm{m}^{-2.7}\right)$ & -0.21 & 0.08 & -0.24 & 0.06 & -0.20 & 0.08 & -0.22 & 0.07 \\
\hline RWT (mm) & -0.18 & 0.10 & -0.20 & 0.08 & -0.17 & 0.12 & -0.19 & 0.09 \\
\hline RVFWT (mm) & -0.02 & 0.49 & -0.06 & 0.43 & -0.10 & 0.38 & -0.08 & 0.39 \\
\hline
\end{tabular}

Abbreviations: BMI, body mass index; LVE $\mathrm{m}_{\mathrm{m}}$, mitral annulus early peak diastolic velocity; LVMi, left-ventricular mass index; LVS, basal interventricular septum peak strain value; LVS $\mathrm{m}_{\mathrm{m}}$, mitral annulus peak systolic velocity; LVSR, basal interventricular septum peak strain rate value; RVFWT, right-ventricular free wall thickness; RWT, relative wall thickness.

Table 5 Multivariate independent predictors of right-ventricular echocardiographic variables in overweight and obese patients

\begin{tabular}{|c|c|c|c|c|c|c|c|c|}
\hline & \multicolumn{2}{|c|}{$R V S_{m}\left(R^{2}=0.22\right)$} & \multicolumn{2}{|c|}{$R V E_{m}\left(\mathrm{R}^{2}=0.30\right)$} & \multicolumn{2}{|c|}{$R V S\left(\mathrm{R}^{2}=0.18\right)$} & \multicolumn{2}{|c|}{$R V S R\left(\mathrm{R}^{2}=0.29\right)$} \\
\hline & $\beta$ & P-value & $\beta$ & P-value & $\beta$ & P-value & $\beta$ & P-value \\
\hline Age (in years) & -0.16 & 0.12 & -0.21 & 0.09 & -0.15 & 0.12 & -0.19 & 0.10 \\
\hline Male gender & 0.19 & 0.14 & 0.22 & 0.12 & 0.24 & 0.09 & 0.15 & 0.22 \\
\hline Mean blood pressure $(\mathrm{mm} \mathrm{Hg})$ & -0.12 & 0.28 & -0.15 & 0.22 & -0.18 & 0.17 & -0.16 & 0.19 \\
\hline RVFWT (mm) & -0.26 & 0.06 & -0.23 & 0.08 & -0.25 & 0.06 & -0.20 & 0.09 \\
\hline
\end{tabular}

Abbreviations: BMI, body mass index; LVMi, left-ventricular mass index; RVE $\mathrm{m}_{\mathrm{m}}$, tricuspid annulus early peak diastolic velocity; RVFWT, right-ventricular free wall thickness; RVS, basal rightventricular free wall peak strain value; RVS $\mathrm{m}_{\mathrm{m}}$, tricuspid annulus peak systolic velocity; RVSR, basal right-ventricular free wall peak strain rate value; RWT, relative wall thickness.

left-ventricular mass index, relative wall thickness and right-ventricular free wall thickness, BMI remained independently related to $S_{\mathrm{m}}$ and $E_{\mathrm{m}}$, and to peak strain and strain rate values $(P<0.01$ for all) for both the left and right ventricles (Tables 4 and 5).

Intraobserver differences were $0.4 \pm 0.8 \mathrm{~cm} \mathrm{~s}^{-1}$ for tissue velocities, $1.8 \pm 1.6 \%$ for strain and $0.1 \pm 0.2 \mathrm{~s}^{-1}$ for strain rate. Interobserver differences were $0.5 \pm 0.9 \mathrm{~cm} \mathrm{~s}^{-1}$ for tissue velocities, $2.0 \pm 1.6 \%$ for strain and $0.2 \pm 0.2 \mathrm{~s}^{-1}$ for strain rate.

\section{DISCUSSION}

Diffusion and accuracy confirmation of tissue Doppler imaging compared with conventional echocardiographic techniques for the 
identification of early abnormalities in systo-diastolic left-ventricular function have been extensively demonstrated, particularly in hypertensive patients. ${ }^{20}$ In addition to diagnostic data, tissue Doppler imaging has also been suggested to be able to provide significant prognostic information, incremental to clinical data and standard echocardiographic variables, for risk stratification of hypertensive patients under treatment. ${ }^{21}$ Moreover, the assessment of right-ventricular function, using conventional echocardiographic indexes, is difficult because of the complex geometry involved; consequently, tissue Doppler imaging measurements have been advocated because of their accuracy and reproducibility in this context.

Some recent evidence suggests an association between obesity and ventricular dysfunction, but data regarding this obesity-related effect in hypertensive patients are lacking. Moreover, the manner and the extension of the negative influence of obesity on the diastolic and/or systolic function in the left and right ventricle remains debated and unclear. $^{6-13}$

To the best of our knowledge, this study represents the first attempt to perform such a complete and detailed echocardiographic evaluation to determine the existence and the extent of an obesityrelated adjunctive depressive effect on left- and right systo-diastolic ventricular dysfunction in hypertensive patients with cutting-edge diagnostic techniques, such as tissue Doppler velocity and strain imaging.

\section{Left-ventricular diastolic function}

Conventional Doppler echocardiography revealed a mild degree of diastolic dysfunction in the referent group of non-obese hypertensive patients without significant obesity-related modification, probably because of its poor sensitivity due to the influence of hemodynamic conditions. These findings are in agreement with those of other authors studying obese subjects; ; $11,12,22,23$ in particular, they are consistent with the results reported by Ballo et al. ${ }^{24}$ in obese hypertensive patients with normal left-ventricular ejection fraction. Moreover, our data add to the evidence reported by Mureddu et al. ${ }^{25}$ that obesity does not significantly increase the prolonged isovolumic relaxation found in non-obese hypertensive patients.

Tissue Doppler imaging, surely more sensitive, confirmed the early diastolic dysfunction in non-obese hypertensive patients, and also revealed in addition a correlation between the degree of diastolic dysfunction and the BMI of the patients' subgroups. This relationship was particularly highlighted by the evaluation of the early-diastolic mitral inflow/mitral annular velocity and the mitral annulus $E_{\mathrm{m}} / A_{\mathrm{m}}$ ratios, in agreement with the findings of most other authors. ${ }^{4,11,12,22,23}$ Notably, in our study, the variation was quite similar in terms of significance for both of these parameters. This finding, confirmed in two other studies, ${ }^{4,12}$ may suggest that the mitral annulus $E_{\mathrm{m}} / A_{\mathrm{m}}$ ratio, which is more feasible and practical to obtain in routine echocardiographic practice and is equal in sensitivity to the early-diastolic mitral inflow/mitral annular velocity ratio, could be helpful in evaluating diastolic function in these patients.

\section{Left-ventricular morphology and systolic function}

Left-ventricular wall thickness and mass indexed to height to the power of 2.7 increased with increasing BMI, reflecting the expected morphological changes according to findings in the existing literature. ${ }^{4,11,12,22-24}$

Even if left-ventricular ejection fraction values were completely normal with no significant differences between the subgroups, mitral annulus $S_{\mathrm{m}}$, and more impressively basal interventricular septum peak strain and peak strain rate values, showed a significant reduction; consequently, these measurements were able to identify and assess the obesity-related sub-clinical left-ventricular systolic dysfunction.

These results challenge previous findings ${ }^{7,9,26}$ and support more recent literature, ${ }^{4,11,12,22,24}$ probably because of the use of newer and more sensitive echocardiographic techniques rather than conventional echocardiographic measurements, such as left-ventricular ejection fraction and fractional shortening, which are relatively insensitive, and thus unable to detect early preclinical changes in left-ventricular function.

\section{Right-ventricular morphology and systo-diastolic function}

In previous studies, the relative role of obesity on right-ventricular morphology and function was difficult to identify because of the significant overlap between obesity and obstructive sleep apnea, and as indeed is the role of obesity relative with other covariates, such as diabetes mellitus and hypertension. ${ }^{27-31}$

In our study, only right-ventricular wall thickness showed a significant variation with increasing BMI and diameter; volume and ejection fraction did not change significantly between subgroups, probably reflecting their insensitivity in assessing early sub-clinical right-ventricular dysfunction.

In contrast, tissue Doppler velocity and strain imaging revealed an obesity-related sub-clinical depressive effect on right-ventricular systo-diastolic function. In fact, tricuspid annulus $S_{\mathrm{m}}$, basal right ventricular free wall peak strain and peak strain rate values, tricuspid annulus $E_{\mathrm{m}}$ and tricuspid annulus $E_{\mathrm{m}} / A_{\mathrm{m}}$ ratio all showed a significant decrease with increasing BMI, suggesting a consistent early sub-clinical obesity-related worsening of both systolic and diastolic right-ventricular function.

These findings extend the previous data reported by Willens et al., ${ }^{12}$ suggesting preserved right-ventricular systolic function in subjects with severe obesity. They also substantially agree with the recent results by Wong et al. ${ }^{13}$ that demonstrated the presence of sub-clinical right-ventricular dysfunction in overweight and obese patients, independently of the presence of obstructive sleep apnea, diabetes mellitus, hypertension or other comorbidities.

\section{Conclusion}

Our study clearly demonstrated the negative impact of obesity on both left- and right-ventricular systo-diastolic function, in terms of adjunctive sub-clinical worsening, in hypertensive patients. These results were made possible using newer echocardiographic techniques, such as tissue Doppler velocity and strain imaging that are more sensitive, and are thus able to identify and assess obesity-related sub-clinical ventricular dysfunction.

A better understanding of the pathophysiology of obesity-related left- and right-ventricular morphological and functional characteristics will enable us to modify the disease process, resulting in the regression of sub-clinical changes. The newer echocardiographic techniques used in this study can provide a robust tool for the early detection of sub-clinical cardiac functional and structural changes, which seems mandatory for an appropriate assessment of cardiovascular risk. These techniques can also be able to evaluate the natural history of these obesity-related changes and the efficacy of therapeutic interventions over time, including weight loss and the treatment of insulin resistance.

\section{CONFLICT OF INTEREST}

The authors declare no conflict of interest. 
1 Clinical guidelines on the identification, evaluation, and treatment of overweight and obesity in adults-the evidence report. National Institutes of Health. Obes Res 1998; 6: 51S-209S.

2 Mokdad AH, Bowman BA, Ford ES, Vinicor F, Marks JS, Koplan JP. The continuing epidemics of obesity and diabetes in the United States. JAMA 2001; 286 1195-1200.

3 Hubert HB, Feinleib M, McNamara PM, Castelli WP. Obesity as an independent risk factor for cardiovascular disease: a 26-year follow-up of participants in the Framingham Heart Study. Circulation 1983; 67: 968-977.

4 Peterson LR, Waggoner AD, Schechtman KB, Meyer T, Gropler RJ, Barzilai B et al. Alterations in left ventricular structure and function in young healthy obese women: assessment by echocardiography and tissue Doppler imaging. J Am Coll Cardiol 2004; 43: 1399-1404.

5 Kenchaiah S, Evans JC, Levy D, Wilson PW, Benjamin EJ, Larson MG et al. Obesity and the risk of heart failure. N Engl J Med 2002; 347: 305-313.

6 Alpert MA. Obesity cardiomyopathy: pathophysiology and evolution of the clinical syndrome. Am J Med Sci 2001; 321: 225-236.

7 Pascual M, Pascual DA, Soria F, Vicente T, Hernández AM, Tébar FJ et al. Effects of isolated obesity on systolic and diastolic left ventricular function. Heart 2003; 89: 1152-1156.

8 Scaglione R, Dichiara MA, Indovina A, Lipari R, Ganguzza A, Parrinello G et al. Left ventricular diastolic and systolic function in normotensive obese subjects: influence of degree and duration of obesity. Eur Heart J 1992; 13: 738-742.

9 Chakko S. Obesity and Ventricular Function in Man: Diastolic Function, In: Alpert MAAJ, ed Armonk New York, NY, 1998, 57-76.

10 Zarich SW, Kowalchuk GJ, McGuire MP, Benotti PN, Mascioli EA, Nesto RW. Left ventricular filling abnormalities in asymptomatic morbid obesity. Am J Cardiol 1991; 68: 377-381.

11 Wong CY, O'Moore-Sullivan T, Leano R, Byrne N, Beller E, Marwick TH. Alterations of left ventricular myocardial characteristics associated with obesity. Circulation 2004; 110: 3081-3087.

12 Willens HJ, Chakko SC, Lowery MH, Byers P, Labrador E, Gallagher A et al. Tissue Doppler imaging of the right and left ventricle in severe obesity (body mass index $>35 \mathrm{~kg} / \mathrm{m}^{2}$ ). Am J Cardiol 2004; 94: 1087-1090.

13 Wong CY, O'Moore-Sullivan T, Leano R, Hukins C, Jenkins C, Marwick TH. Association of subclinical right ventricular dysfunction with obesity. J Am Coll Cardiol 2006; 47: 611-616.

14 Schiller NB, Shah PM, Crawford M, DeMaria A, Devereux R, Feigenbaum $\mathrm{H}$ et al. Recommendations for quantitation of the left ventricle by two-dimensional echocardiography. American Society of Echocardiography Committee on Standards, Subcommittee on Quantitation of Two-Dimensional Echocardiograms. J Am Soc Echocardiogr 1989; 2: 358-367.

15 Sahn DJ, DeMaria A, Kisslo J, Weyman A. Recommendations regarding quantitation in M-mode echocardiography: results of a survey of echocardiographic measurements. Circulation 1978; 58: 1072-1083.
16 Devereux RB, Reichek N. Echocardiographic determination of left ventricular mass in man. Anatomic validation of the method. Circulation 1977; 55: 613-618.

17 Shan K, Bick RJ, Poindexter BJ, Shimoni S, Letsou GV, Reardon MJ et al. Relation of tissue Doppler-derived myocardial velocities to myocardial structure and beta-adrenergic receptor density in humans. J Am Coll Cardiol 2000; 36: 891-896.

18 Urheim S, Edvardsen T, Torp H, Angelsen B, Smiseth OA. Myocardial strain by Doppler echocardiography. Validation of a new method to quantify regional myocardial function. Circulation 2000; 102: 1158-1164.

19 Greenberg NL, Firstenberg MS, Castro PL, Main M, Travaglini A, Odabashian JA et al. Doppler-derived myocardial systolic strain rate is a strong index of left ventricular contractility. Circulation 2002; 105: 99-105.

20 Leggio M, Sgorbini L, Pugliese M, Mazza A, Bendini MG, Fera MS et al. Systo-diastolic ventricular function in patients with hypertension: an echocardiographic tissue doppler imaging evaluation study. Int J Cardiovasc Imaging 2007; 23: 177-184.

21 Wang M, Yip GW, Wang AY, Zhang Y, Ho PY, Tse MK et al. Tissue Doppler imaging provides incremental prognostic value in patients with systemic hypertension and left ventricular hypertrophy. J Hypertens 2005; 23: 183-191.

22 Di Salvo G, Pacileo G, Del Giudice EM, Natale F, Limongelli G, Verrengia M et al. Abnormal myocardial deformation properties in obese, non-hypertensive children: an ambulatory blood pressure monitoring, standard echocardiographic, and strain rate imaging study. Eur Heart J 2006; 27: 2689-2695.

23 Sharpe JA, Naylor LH, Jones TW, Davis EA, O'Driscoll G, Ramsay JM et al. Impact of obesity on diastolic function in subjects $<$ or $=16$ years of age. Am J Cardiol 2006; 98: 691-693.

24 Ballo P, Zacà V, Giacomin E, Galderisi M, Mondillo S. Impact of obesity on left ventricular systolic function in hypertensive subjects with normal ejection fraction. Int J Cardiol 2010; 141: 316-320.

25 Mureddu GF, de Simone G, Greco R, Rosato GF, Contaldo F. Left ventricular filling in arterial hypertension. Influence of obesity and hemodynamic and structural confounders. Hypertension 1997; 29: 544-550.

26 lacobellis G, Ribaudo MC, Leto G, Zappaterreno A, Vecci E, Di Mario U et al. Influence of excess fat on cardiac morphology and function: study in uncomplicated obesity. Obes Res 2002; 10: 767-773.

27 Guidry UC, Mendes LA, Evans JC, Levy D, O'Connor GT, Larson MG et al. Echocardiographic features of the right heart in sleep-disordered breathing: the Framingham Heart Study. Am J Respir Crit Care Med 2001; 164: 933-938.

28 Berman EJ, DiBenedetto RJ, Causey DE, Mims T, Conneff M, Goodman LS et al. Right ventricular hypertrophy detected by echocardiography in patients with newly diagnosed obstructive sleep apnea. Chest 1991; 100: 347-350.

29 Whyte KF, Douglas NJ. Peripheral edema in the sleep apnea/hypopnea syndrome. Sleep 1991; 14: 354-356.

30 Sanner BM, Konermann M, Sturm A, Müller HJ, Zidek W. Right ventricular dysfunction in patients with obstructive sleep apnoea syndrome. Eur Respir J 1997; 10: 2079-2083.

31 Nahmias J, Lao R, Karetzky M. Right ventricular dysfunction in obstructive sleep apnoea: reversal with nasal continuous positive airway pressure. Eur Respir J 1996; 9: 945-951. 